\title{
A CONFIGURAÇÃo JURÍDICA DO SERVIÇO PÚBLICO*
}

CAIO TÁCITO

Entre as mais árduas missões do jurista, no campo do Direito Administrativo, figura a de conceituar, adequadamente, o serviço público. Embora ocorra, fragmentariamente, a qualificação legal das atividades ou órgãos do Estado suscetíveis dessa designação não se torna fácil condensar, em síntese definidora, os elementos que o identifiquem, no tempo e no espaço.

A noção é fugidia e variável, assemelhando-se, na disparidade de critérios e definições, a um diálogo de surdos, em que não se entendem os interlocutores, conforme a sátira de Marcel Waline (Droit administratif, $8^{a}$ ed., 1959, p. 620).

Considera-a Renato Alessi "un delle più incerte e nebulose di tutto quanto il campo del diritto publico".

Na França, onde a noção de serviço público chegou a substituir, na concepção de Duguit, a idéia da soberania com elemento constitutivo do Estado (Traité de droit constitutionnel, $2^{a}$ ed., vol. II, pág. 54) e se tornou, através da chamada escola do Serviço Público (Jèze, Bonnard, Rolland e Laubadère), o ponto nuclear do Direito Administrativo, a sua instabilidade e incerteza, especialmente na discriminação da competência jurisdicional entre a Justiça Administrativa e a Comum, levou a que se proclamasse a existência da crise da noção do serviço público (Corail, Morange, Chenot, Rivero, Demiched).

No mais completo estudo sobre o tema, da lavra de Umberto Pototschning, Professor de Direito Administrativo de Pavia (I pubblici servizi, 1964, coleção Diritto e amministrazione, dirigida por Feliciano Benvenuti) espelha-se a acentuada variedade com que, no direito italiano e no comparado, se apresentam as definições e classificações do serviço público.

- Palestra no XVII Congresso Brasileiro de Direito Administrativo, setembro 2003

R. Dir. Adm., Rio de Janeiro, 233: 373-376, Jul./Set. 2003 
Observei, em trabalho anterior, que não há um conceito apriorístico de serviço público, elastecendo-se o seu âmbito na medida em que se expande a presença do Estado nos domínios da vida social contemporânea.

A relatividade da noção do serviço público foi acentuada por Themístocles Cavalcanti, com apoio em Gaston Jèze, e se reforça na lição pragmática de Aliomar Baleeiro, quando lembra que "a supervisão do culto religioso pode pertencer à competência dum Ministro de Estado, como foi no Brasil e na França e, mais tarde, pode ser proibida no orçamento, como acontece hoje, nesses mesmos países" (Clínica Fiscal, 1958, p. 163).

Costuma-se, ainda, opor, na caracterização do serviço público, a definição material ou funcional à concepção orgânica ou formal.

A primeira tem em mira a atividade de interesse geral a que se destina o serviço; a segunda considera dominante o organismo administrativo que o desempenha.

Ao conceito jurídico do serviço público, como expressão típica de atividade estatal, poder-se-á, ainda, agregar a sua significação econômica, social, política ou fiscal, nem sempre coincidente com o sentido orgânico ou administrativo da expressão. A lei considera mesmo, para fins determinados, como serviço público lato sensu, atividades que são de exercício privado, como, por exemplo, a advocacia, o jornalismo, ou a assistência social.

É certo que o âmbito do serviço público exprime as oscilações políticas do Estado. A moderna tendência intervencionista no domínio econômico e social atraiu para o terreno da atividade administrativa um elenco de serviços que não figuram nos modelos clássicos da Administração Pública.

Trata-se, no entanto, de mera exacerbação ou agravamento de uma dicotomia entre os fins administrativos do Estado, que já fazia distinguir, nos autores mais amigos, a atividade jurídica e a atividade social da administração Pública. Desenvolvida especialmente por Orlando em seu clássico Trattato di diritto amministrativo, foi endossada no verbete de Guido Zanobini para a Enciclopedia del diritto (1958, vol. II, p. 236). Na primeira atividade, a jurídica, como exercício da soberania do Estado e de seu poder de império, atende-se à preservação do direito objetivo, à ordem pública, à paz e à segurança coletivas. É uma atividade de tutela do ordenamento jurídico, caracterizando-se pelo poder de coação próprio e privativo do Estado. $\mathrm{Na}$ atividade social, ao contrário, a administração cuida de assuntos de interesse coletivo, visando ao bem-estar e ao progresso social, mediante o fornecimento de serviços aos particulares. A primeira atividade corresponde uma ação administrativa: à segunda, uma prestação administrativa.

É nesse sentido que, entre nós, Mário Mazagão, divide o serviço público administrativo em duas categorias: serviços concernentes à atividade essencial do Estado (tutela do direito) e serviços relativos à atividade facultativa (promoção do bem-estar geral, cultura e progresso), atribuindo-lhes, respectivamente, a qualidade de ação jurídica e ação social.

Certamente a evolução moderna do Estado exaltou de tal forma a sua participação na ordem social, que a essencialidade passou a abranger tanto os encargos tradicionais de garantias da ordem jurídica como as prestações administrativas que são emanações dos modernos direitos econômicos e sociais do homem, tão relevan- 
tes, na era da socialização do direito, como os direitos individuais o foram na instituição da ordem liberal.

Todavia, uma sensível diferença entre os serviços públicos que, por sua natureza, são próprios e privativos do Estado e aqueles que, passíveis em tese de execução particular, são absorvidos pelo Estado, em regime de monopólio ou de concorrência com a iniciativa privada. Aos primeiros poderíamos chamar de serviços estatais originários ou congênitos; aos últimos, de serviços estatais derivados ou adquiridos.

O mesmo sentido ontológico inspirou, na doutrina italiana, com endereço ao campo do direito penal, a distinção entre função pública e serviço público.

Como esclarece Miele, a função pública é a atividade endereçada aos fins essenciais do Estado (como a justiça, a segurança pública, a defesa nacional) enquanto o serviço público representa a atividade do Estado visando aos objetivos de bem-estar social e à satisfação das necessidades individuais.

Segundo Giannini, a função pública, fundada no poder soberano, é atividade necessária do Estado. Serviço público, ao contrário, é contrário, é atividade que somente adquire esse caráter quando o Estado dela se faz titular, podendo, em princípio, ser exercida pelos particulares.

Outra variante dessa mesma classificação exprime-se através da opinião de Arnaldo de Valles, quando separa os serviços administrativos e os serviços públicos.

Se o interesse satisfeito na atividade pública é próprio da coletividade entendida em seu todo, e não o resultante da soma de interesses individuais, temos um serviço administrativo.

Quando o interesse coletivo é a soma de interesses individuais, de tal forma que o escopo social se traduz na satisfação imediata de necessidades individuais, mediante vantagem direta a certos destinatários, temos um serviço público.

Os mesmos conceitos são expendidos por Marcello Caetano, na definição que propõe para o serviço público como "o serviço administrativo cujo objeto consiste em facultar a quantos dele careçam os meios idôneos para a satisfação de uma necessidade coletiva individualmente sentida".

Esclarecendo a discriminação em termos que interessam, de perto, ao objeto deste estudo, Arturo Lentini assinala que "la funzione publica è caratterizzata dalla potestà e dalla distinazione dell'atività amministrativa ai cittadini considerati uti universi e non uti singuli; I servizi pubblici riguardano I cittadini uti singuli e non uti universi".

Atingimos, assim, a uma forma de classificação do serviço público, que tem em mira o grau de utilidade auferida pelos seus destinatários.

A prestação administrativa do serviço compreende duas categorias. A primeira consiste na atividade dirigida a produzir uma utilidade genérica aos cidadãos uti universi, sem possibilidade de medida da utilidade que cada um individualmente usufrui.

Na segunda categoria, ao contrário, a atividade se dirige a produzir uma utilidade específica para determinados cidadãos que se valem do serviço posto à disposição de todos, ou seja, atividade que se traduz em uma vantagem usufruída pelos cidadãos uti singuli. 
Não se abandona, nessa qualificação de uso, o princípio da generalidade do serviço público, como bem observa Villegas Basavilbaso: "O serviço público é sempre destinado a todos, e não a determinada pessoa... (mas) a sua prestação pode ser uti universi e uti singuli. A prestação é uti universi quando não há usuário propriamente dito, quando o Estado (lato sensu) é quem imediata e diretamente o utiliza, para benefício da coletividade. A prestação é uti singuli, quando existe usuário, quando ela beneficia imediata e diretamente a uma pessoa ou várias pessoas indeterminadas, isto é, à generalidade do púbico."

Os serviços públicos uti universi, por isto mesmo que atendem de "forma direta e indivisível à coletividade" (Bielsa, Compendio de derecho público, 1952, vol. II, p. 94), avizinham-se do conceito da função pública, como acima exposto, ou seja, como atividade própria e exclusiva do Estado.

Documenta essa afirmação o testemunho autorizado de Cino Vitta: "sono invece denominante presso di noi pubbliche funzioni quelle che sono destinate a profitto della collettività indistintamente pressa, cioè dei cittadini considerati piú uti universi che uti singuli".

Todas essas classificações do serviço público apresentam um traço comum, através da sua diversidade de critérios: o reconhecimento da antinomia entre duas modalidades ou categorias de ação administrativa.

Temos, de uma parte, uma forma de ação geral e indivisível do serviço público, que atende diretamente a interesses coletivos indiscriminados (uti universi) e corresponde a uma atividade soberana e privativa do Estado.

De outra parte, ocorrem prestações de serviço que, embora genéricas quanto à sua disponibilidade, visam a satisfazer interesses que se podem individualizar entre determinadas pessoas, que as usufruem diretamente (uti singuli). Tais prestações administrativas não são privativas do Estado ratione materiae, não emanam de seu poder soberano, embora possam constituir monopólio estatal de lege.

A essas duas categorias é que se deve atribuir, respectivamente, a designação de serviço público geral e serviço público especial, segundo a terminologia de Vitti del Marco.

Não se trata de uma discriminação de base territorial, ou qualitativa, mas de um conceito qualitativo, vinculado à natureza intrínseca do serviço público, ontologicamente considerado. 